Conclusions This is an important topic. Results are still emerging including an independent evaluation due in September 2017. Improvements in clinical processes (quality and reliability) depend on good engagement with acute clinicians. Quality improvement methods helped, but other enablers are often required.

\section{P-180 COLLABORATION, COMMUNITY AND CREATIVITY}

Lynn Kelly. St Catherine's Hospice, Preston, UK

\subsection{6/bmispcare-2017-hospice.205}

Background A key objective of the newly formed Knowledge Exchange Directorate in 2015 was to collaborate with other organisations to support the achievement of St Catherine's Hospice's (SCH) aim 'To help more people have quality of life to the end of life'. A formal collaboration with Higher Education was a high priority and in late 2015 discussions began with the University of Central Lancashire (UCLan) to explore a more formal relationship.

Aim of the Collaboration To work together to explore opportunities for the joint development of: the expertise residing in UCLan and $\mathrm{SCH}$ for the benefit of local people and the local economy; educational opportunities through potential collaborative provision research and academic projects, including academic updating and sharing of good practice links within their respective industries to provide students with hands-on practical experience; joint bids for external funding to support the above.

Methods A formal three- year Memorandum of Understanding was signed with UCLan to lay out the objectives of the partnership and the principles of collaboration alongside statements on intellectual property and confidentiality.

Results Include

- New opportunities for students from the College of Health and Wellbeing and Medical School to support understanding end of life care. SCH to be included in the pilot of the Physician's Associate role

- Support to help SCH develop its communications strategy including a project by MBA students and a facilitated planning day delivered by the Leadership Hub

- Joint bid for research project on the use of communications technology in end of life care.

- Exploring potential for placements from events, communications and creative/design students.

Conclusion The whole is greater than the sum of each part. $\mathrm{SCH}$ has to offer real world issues, experience, and community involvement; UCLan offers research, evidence-based knowledge and developing talent; together there is innovation, thought leadership and impact through social change.

\section{P-181 PREPARED TO CARE? WHAT ARE MENTAL HEALTH AND PALLIATIVE CARE PROFESSIONALS' EXPERIENCE OF COLLABORATING TOGETHER WHEN SUPPORTING PATIENTS WITH SEVERE PERSISTENT MENTAL ILLNESS AND PALLIATIVE CARE NEEDS?}

${ }^{1}$ Nicky Wood, ${ }^{2}$ Steve Iwasky, ${ }^{3}$ Sue Bailey, ${ }^{4}$ May Pheasant. ${ }^{1}$ sabel Hospice, Welwyn Garden City, UK; ${ }^{2} \mathrm{MH}$ Raid team; ${ }^{3}$ Garden House Hospice, Letchworth Garden City, UK; ${ }^{4}$ Lister Hospital, Stevenage, UK

10.1136/bmjspcare-2017-hospice.206
Background Much has been written in the past year about inequalities in palliative care. Patients with severe mental illness often present late with an advanced diagnosis for which palliative care is the only option (Ellison, 2008). Research in this area is lacking, no statistical evidence exists as to numbers of patients requiring collaboration from both specialties (Addington-Hall, 2000). A recent American study highlighted barriers present when caring for mental health patients with palliative care needs; as a result this study called for greater collaboration between palliative care and mental health specialties (Morgan, 2016). However, there is very little research to highlight the experience of collaboration between these two specialties.

Aim As a result this scoping session aims to examine the working relationships between mental health and palliative care health care professionals (HCPs) when caring for patients with severe mental illness and also a palliative care diagnosis. The session wants to understand both positive and negative experiences of collaboration in order to highlight the support these patients receive.

Method A scoping session is due to take place on 22 June. 15 HCPs from various palliative care settings and 15 HCPs from mental health settings having been invited. On arrival all participants will be asked to fill in a questionnaire. Following presentations from both specialties there will be mixed group work. Facilitators within the groups will gather information through various means to add weight to the questionnaire.

Conclusion Everyone has a right to high standards of palliative care. This scoping session aims to explore how collaboration is working and if there are gaps or barriers which prevent cohesive working. This session aims to be responsive to issues highlighted and to provide recommendation for improved future collaborative practice, with the ultimate goal of reducing inequalities in care experienced by this group of patients.

\section{P-182 THE DEVELOPMENT OF A CHILDREN'S HOSPICE NEONATAL LINK TO IMPROVE PERINATAL PALLIATIVE CARE}

Katrina Williams. Claire House Children's Hospice, Merseyside, UK

10.1136/bmjspcare-2017-hospice.207

Background Perinatal palliative care (PPC) is an evolving specialty committed to providing care for foetuses/babies with a life-limiting condition diagnosed in the antenatal/neonatal period, as well as supporting the parents and extended family. However, the number of referrals for hospice support was few and far between.

Aim(s) Increase awareness of hospice services amongst tertiary centres within Cheshire and Merseyside

Create consistency to families of a choice of place of care and death; hospital, hospice or home

Provide specialist palliative care through diagnosis, birth, child's life, and death.

Methods Links have been developed in two neonatal units within the hospice catchment area. This included regular presence on ward rounds and education about hospice services, thus creating good collaborative working between hospital, hospice and families.

Results Since the initial development of links in 2014, referrals (aged 0-1 years) accepted for hospice care have increased by 216\%. This has had a dramatic impact on all services offered 
by the hospice, including a $167 \%$ increase in neonatal referrals for use of the bereavement suite. The value of hospice services has been clearly acknowledged by tertiary centres, along with very positive feedback direct from families.

'We miss Emmalyn every day but we are so thankful that Claire House helped us create such happy memories that we can cherish forever.' Victoria, mum of Emmalyn who was diagnosed with Trisomy 18 and lived for 26 days.

Conclusion Clearly the children's hospice has a definitive role within PPC. The presence of hospice staff within tertiary centres has enabled good palliative care planning with all relevant professionals of the multi-disciplinary team. Thus, providing seamless and compassionate support for families, with a choice of their preferred place of care. We aspire to develop stronger partnerships in the future, with the development of a jointly commissioned post (hospital/hospice) to lead PPC across Cheshire and Merseyside.

\section{P-183 COLLABORATING WITH LOCAL SERVICES TO IMPROVE ACCESS TO EQUIPMENT TO SUPPORT PREFERRED PLACE OF CARE AND DEATH}

Liz Strachan. Princess Alice Hospice, Esher, UK

\subsection{6/bmjspcare-2017-hospice.208}

Background To enable patients to safely remain in their preferred place of care (PPC) or death (PPD) and to maximise their independence within the limitations of their illness, specialist equipment may be needed.

Historically, hospice therapists had limited access to equipment which had been either bought by the hospice, or donated. To secure other equipment, lengthy reports were completed by hospice occupational therapists (OT) and then sent to the OT within one of 12 social services locality teams. They, in turn, ordered the equipment through Community Equipment Services (CES) on the hospice therapist's behalf. This sometimes led to confusion and delays of equipment being delivered, resulting in patients not fulfilling their PPC/ PPD.

Aim To have the means to provide equipment to patients in a timely fashion to support PPC/PPD.

Results Following three years of collaborative working with the Clinical Lead for Equipment, locality teams and Integrated Community Equipment Services (CES) across Surrey, a peripheral store is now on site at the hospice. This allows instant access to a range of equipment which can be immediately supplied to patients. To facilitate this, each OT and physiotherapist now has an individual PIN number. This new process increases the possibility of achieving a safe environment for PPC and PPD.

Conclusion This has led to the following benefits:

- Enabled more patients to achieve their PPC/PPD

- Supported patients to maximise their independence in their own environment

- Reduced administrative time for hospice and social services therapists

- Freed up time for increased face-to-face interventions

- Reduced delivery costs for social services locality teams

- Increased job satisfaction for hospice therapists.
Future development of this project will include:

- Negotiating with social service teams that are currently not involved in this collaborative working

- To resolve challenges in relation to Continuing Health Care funded provision of equipment.

\section{P-184 DELIVERING AN INTEGRATED END OF LIFE CARE SERVICE - IS IT SUSTAINABLE SIX YEARS ON?}

Kate Heaps, Alison McCarthy, Jonathan Devlin. Greenwich and Bexley Community Hospice, Abbey Wood, UK

\subsection{6/bmjspcare-2017-hospice.209}

Background The Greenwich Care Partnership (GCP) was born out of the Marie Curie Delivering Choice Programme (DCP). Three service providers developed the service, with the hospice as prime contractor and two sub-contracted partners. The service has been in operation since 2011.

Service Aims

- To increase the number of people who are able to die in their place of choice

- To ensure appropriate health and personal care services

- To provide family support.

Service Approach The service operates alongside core services to support high quality care across four areas:

- Care co-ordination

- Rapid Response Service - Out of Hours

- Personal care and support

- Night care.

Elements are provided by different providers working together to ensure seamless care 24/7.

The following data will be reported:

- Activity data collected over the duration of the project

- HR information regarding staff retention and staff satisfaction ratings

- VOICES feedback.

Service outcomes:

- Sustained increase in home and hospice deaths

- Maintained reduction in hospital admissions, length of stay and deaths

- Low staff turnover and high job satisfaction for carers in service

- Catalysing further integration and service innovation

- High patient and carer satisfaction.

Challenges:

- 'Flat' funding with growth in service activity

- Organisational change at CCG and continuity of communication with partner organisations

- Continued lack of GP engagement in end of life care.

Conclusion The service continues to deliver its intended outcomes and has acted as a catalyst for further innovation and integration. Despite a number of challenges throughout the project, the service remains sustainable and is a key part of the hospice service. 